\title{
A Case of the Scalenus Anterior Muscle Lying Behind the Fifth Cervical Nerve Root
}

\author{
By \\ Tsugane MH, Murakami G and Yasuda $M^{*}$ \\ Department of Anatomy, Sapporo Medical University School of Medicine, South 1, West 17, Sapporo, 060-8556 Japan \\ * Department of Anatomy, Hiroshima University School of Medicine, 1-2-3 kasumi, Minami-Ku, Hiroshima, \\ 734-8551 Japan \\ - Received for Publication, June 8, 1998 \\ Key Words: Scalenus anterior muscle, Cervical nerve root, Innervation, Nerve fiber analysis, Human gross anatomy

\begin{abstract}
Summary: Muscle slip composition and innervation was minutely examined in the case of the scalenus anterior muscle lying behind the 5th cervical nerve root. This minor change of topography deeply involved the muscle-nerve relationships of the entire muscle. Critical observations were as follows: (1) lower and unusual origins of the muscle; (2) irregular innervation with regard to the nerve elements and their approach to the muscle. This evidence suggested that abnormal migration, splitting and fusion of the muscle anlage had occurred during the development of the variant.
\end{abstract}

Although an aberrant muscle slip of the scalenus anterior muscle, lying behind the ventral nerve root, appears to be relatively common (Eisler, 1912; Serizawa, 1968), the muscle lies entirely behind the 5 th cervical nerve root in less than 3\% (Makhoul and Machleder, 1992; Harry et al., 1997). However, no one has described the pattern of innervation relating to these variations of the muscle. Koizumi (1989) suggested that abnormal muscle splitting of the coracobrachialis muscle occurs in combination with variations of its topographical relationship with the musculocutaneous nerve, a relationship that appears to be similar to that of the muscle and nerve in the present case. The aim of this report was to examine the innervation in detail in a rare variant of the scalenus anterior muscle to obtain a better understanding of the configuration of the muscle and nerve in this region.

\section{Materials and Methods}

The specimen was the left side of a donated female cadaver, aged 87 years, initially examined during a dissecting practice course for medical students in Hiroshima University in 1995. The cervicobrachial plexus region of the specimen was preserved for investigation and was dissected minutely under a stereo-binocular scope. To clarify whether the ventral or dorsal element of the nerve plexus innervated the muscle, nerve fiber analysis was performed within a limited portion of the plexus from which nerve twigs supllying the muscle issued. The identification of the elements was based on Kida (1990), i.e., in this case, the ventral element was closely related to the sympathtic nerves, while the dorsal element occupied a position near the dorsal scapular nerve. Variations were not evident in the same region of the contralateral side of the specimen.

\section{Results}

The subclavian artery and the 6th-8th cervical ventral nerve roots (C6-C8) passed dorsal to the scalenus anterior muscle, as usual, whereas only the 5 th cervical ventral nerve root (C5) passed ventral (Fig. 1). The variant muscle was divided into six muscle slips, named slips I-VI, according to their origin, insertion and topographical relationships to the nerves (Fig. 2); each slip overlaid anterosuperiorly the slip of the next lowest number (eg. slip III laid antero-superiorly to slip II).

Muscle slip I, the smallest one, connected between the ventral surfaces of the scaleni anterior 
and medius muscles. A nerve twig, arising from the upper side of $\mathrm{C6}$ and crossing dorsally to $\mathrm{C5}$, approached from the dorsal aspect of the slip and innervated it.

Muscle slips II and III originated from the anterior surface fascia of the scalenus medius muscle and inserted onto the first rib. Slip II was innervated by a twig arising from the dorsal element of C5. This twig was closely related to a root of the dorsal scapular nerve, but a nerve fiber connection with the latter was not evident. Slip III was innervated by another twig from the upper side of C6. Nerve twigs approached either slip II or III from the dorsal aspect.

Muscle slip IV extended between the anterior tubercle of the 6th cervical transverse process and the first rib. The supplying nerve arose from the ventral element of $\mathrm{C} 5$, forming a common trunk with a communicating branch of $\mathrm{C5}$ to the stellate ganglion, and approached from the ventral aspect of slip IV.

Muscle slips V and VI both originated from the 7th anterior tubercle and inserted onto the first rib. Nerve twigs which given from the ventral element of C6 (slips V and VI) and C7 (slip V) approached from the dorsal aspect of these slips and innervated them. These nerve twigs were tightly fasciculated with communicating branches of $\mathrm{C} 6$ or $\mathrm{C} 7$ to the stellate ganglion, respectively.

In contrast, variations were not evident in the basic configuration of the nerve plexus and vascular ramification, or in the cervical vertebrae. The levator scapulae muscle was innervated by the 3rd and 4th cervical ventral nerve roots (C3 and $\mathrm{C} 4)$. The dorsal scapular nerve (origin, C5), long thoracic nerve, suprascapular nerve (C5 and C6), phrenic nerve (C4) and accessory phrenic nerve (C4 and C5) were observed as usual. A nerve twig to the subclavius muscle had been missed when this case was found. The number of vertebrae and the course of the vertebral artery were also normal. Nerve twigs to the scalenus medius muscle originated from the dorsal elements of $\mathrm{C} 4$ and $\mathrm{C} 5$ and were closely related to the dorsal scapular nerve, and also from the ventral element of C6.

Consequently, this variation of the scalene anterior muscle was summarized as follows: 1 . Unusual origin of muscle, i.e., lower and/or fascial origin (the usual origin in Japanese: the 4th-6th anterior tubercle (Serizawa 1968)); 2. Unusual pattern of innervation to each muscle slip (the usual innervation of each slip: 2-3 segmental nerves approaching from the dorsal aspect (Eisler, 1912; Serizawa, 1968)); 3. Innervation by both ventral and dorsal elements of the plexus (the usual pattern: by the most ventral element of the cervico- brachial plexus (Kida, 1990)).

\section{Discussion}

Although the overall shape of the scalenus anterior muscle variant appeared almost normal, an unusual pattern of innervation (the irregular approach of nerve twigs to the muscle and the absence of 2-3 nerve segments innervating one muscle slip attached to one anterior tubercle) as well as an inferior dislocation of the muscle origin was unexpectedly evident. Moreover, each mucle slip seemed to be innervated at random by either a ventral or dorsal element of the nerve plexus. This evidence might suggest abnormal migration, splitting and fusion of the muscle anlage during the development of the variation, as has been suggested to occur in the formation of aberrant slips of the levator scapulae muscle (Eisler, 1912; Yamazaki and Takahashi, 1983). Based on the fiber element of each nerve supplying to the muscle slip, the superior portion of the variant seemed to be a part of the scalenus medius muscle, i.e., the ventral part presented by Nakano et al. (1979), which replaced the missing "original" superior portion of the scalenus anterior. By contrast, the inferior portion seemed to maintain an almost original figure of the scalenus anterior muscle. Consequently, we considered that an unusal topographical relationship between a muscle and its supplying nerve often indicates an abnormal development of the muscle.

Previously, a "major" variation relating to the scalenus anterior muscle such as the subclavian artery passing before the muscle (Dolgo-Saburoff, 1933; Inuzuka, 1989; Harry et al., 1997) has been discussed in the context of vascular embryology. However, we thought that minute muscle dissection and nerve fiber analysis might reveal both hidden and conspicuous changes concerning the innervation, since such a "minor" change of the topography as seen in the present variant (Fig. 1) deeply involved the muscle-nerve relationships of the entire muscle.

\section{References}

1) Dolgo-Saburoff B. Zur Frage über die Lagebezieungen zwischen der A. subclavia und der Scalenusmuskulatur beim Menschen. Anat Anz 1933; 76:97-113.

2) Eisler P. Die Muskeln des Stammes. In: Handbuch der Anatomie des Menschen (Bardeleben, K.V. ed). II Bd, II Abt., I Teil, pp. 298-307, 374-375, Gustav Fischer, Jena, 1912.

3) Harry WG, Bennett JDC and Guha SC. Scalene muscles and the brachial plexus: Anatomical variations and their clinical significance. Clin Anat 1997; 10:250-252. 
4) Inuzuka $\mathbf{N}$. A case of the scalene anterior muscle passing behind the left subclavian artery. Okajima Folia Anat Jpn 1989; 66:229-240.

5) Kida M. Stratum-structure of the spinal nerves in the understanding of body structure. Acta Anat Nippon 1990; 65:75-82.

6) Koizumi M. A morphological study on the coracobrachialis muscle. Acta Anat. Nippon. 1989; 64:18-35. (in Japanese with English abstract)

7) Makhoul RG and Machleder HI. Developmental anomalies at the thoracic outlet: An analysis of 200 consecutive cases. J Vasc Surg 1992; 16:534-545.

8) Nakano $Y$, Kato $K$, Nakazawa $S$ and Sato T. On the lamination and innervation of the scalenus medius muscle. Acta Anat Nippon 1979; 54:103-104. (in Japanese)

9) Serizawa $M$. On the scalene anterior muscle in adult Japanese. Nippon Medical School J 1968; 35:188-202. (in Japanese with English abstract)

10) Yamazaki $M$, Takahashi $H$. On the first bundle of levator scapulae muscle additionally supplied by a branch from the second dorsal cervical ramus. Acta Anat Nippon 1983; 58:51-58. 


\section{Explanation of Figures}

\section{Plate I}

Fig. 1. Line-drawing of a variant of the scalenus anterior muscle and its surroundings. Antero-lateral view. Muscle slip numbers I-VI correspond to those in Fig. 2.

S.ant, Scalenus anterior muscle; S.med, Scalenus medius muscle; SCM, Sternocleidomastoideus muscle; SA 1 and 2, Serratus anterior muscle; LS 1-3, Levator scapulae muscle; Rh, Rhomboideus muscles; Tp, Trapezius muscle; C2-6, Ventral rami of the cervical nerves; Ggl, Sympathetic ganglion (the stellate ganglion is not seen.); X, Vagus nerve; XI, Accessorius nerve; Ansa, Ansa cervicalis; SS, Suprascapular nerve; AX, Axillaris nerve; R, Radialis nerve; MC, Musculocutaneous nerve; M, Medianus nerve; $\mathrm{U}$, Ulnaris nerve; TL, Thoracicus longus nerve; PH, Phrenic nerve; A or V, Axillary artery or Vein. 


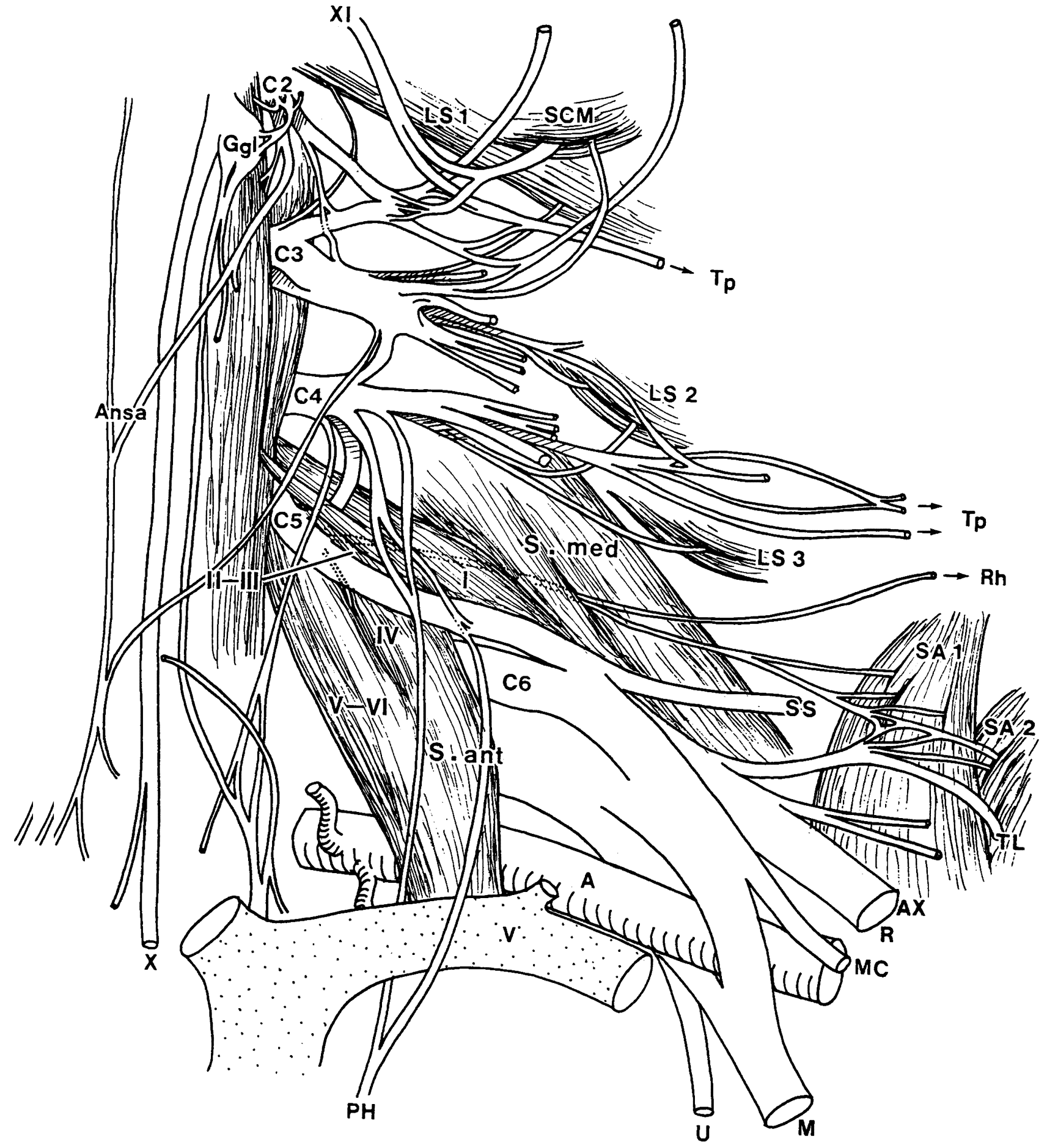




\section{Plate II}

Fig. 2. Schematic drawing of muscle slip composition and innervation.

Anterior view. Muscle slips I-VI had been separated from each other. Note the approach and origin of nerve twig(s) supplying each slip. C4-7, Ventral ramus of the cervical nerve; DS, Dorsal scapular nerve; Ggl, Stellate ganglion; TC, Transverse cervical artery. 


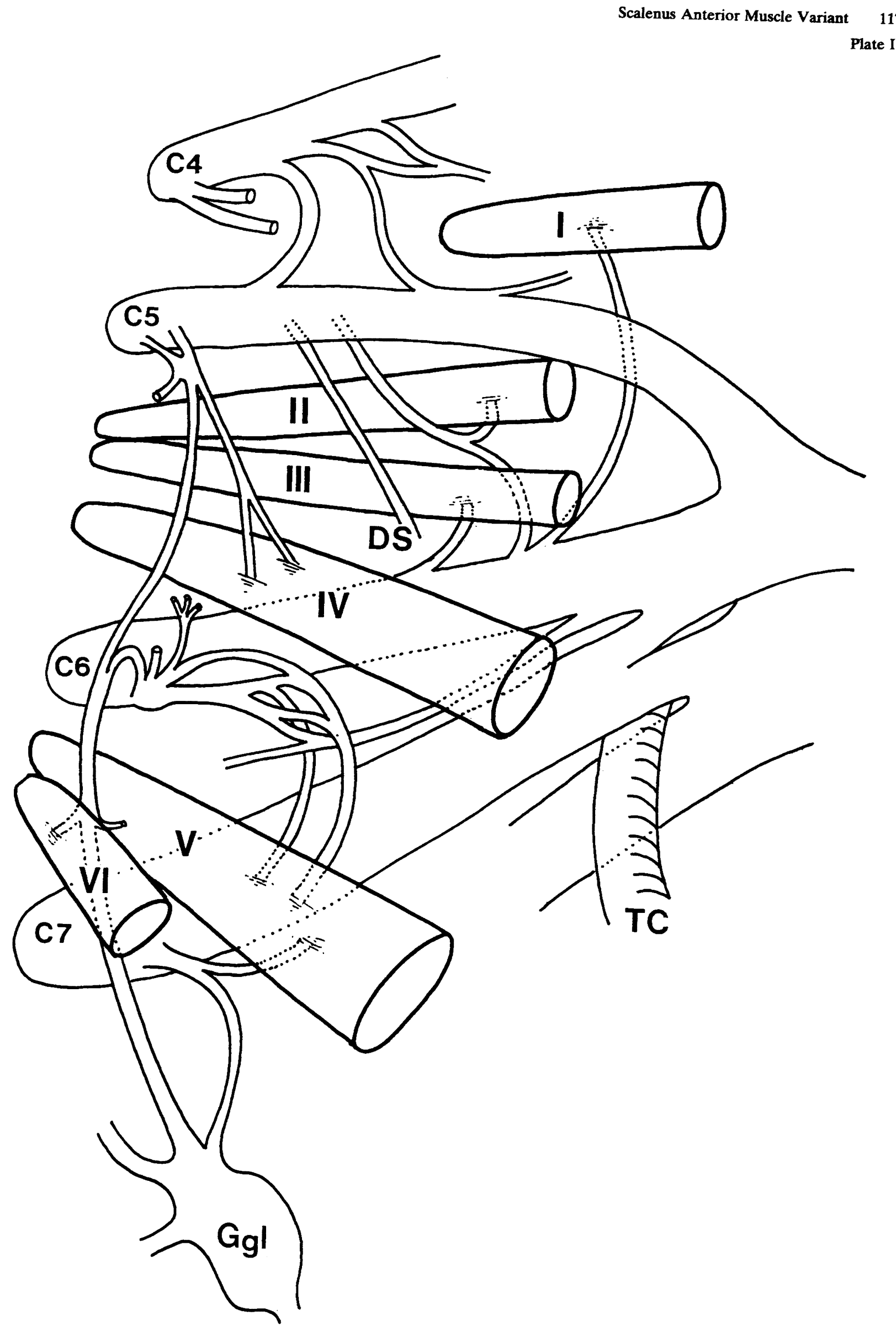

